\title{
Biogenic amines shift during the pre-reproductive to reproductive transition in the small carpenter bee, Ceratina calcarata
}

\author{
Chelsea N. Cook ${ }^{1}$, Sarah P. Lawson ${ }^{2}$, Colin S. Brent ${ }^{3}$, Sandra M. Rehan ${ }^{2}$ \\ ${ }^{1}$ School of Life Sciences, Arizona State University, P.O. Box 874501, Tempe, AZ 85287-4501, USA \\ ${ }^{2}$ Department of Biological Sciences, University of New Hampshire, Durham, NH 03824, USA \\ ${ }^{3}$ US Department of Agriculture, Arid-Land Agricultural Research Center, Maricopa, AZ 85138, USA
}

Received 25 May 2018 - Revised 27 November 2018 - Accepted 10 December 2018

\begin{abstract}
The shift from solitary to social living is a major evolutionary transition for social insects. In bees, this transition is marked by certain females becoming reproductive and reducing their role in nest and offspring care, duties that are assumed by other females. Biogenic amines play a significant role in regulating these behaviors in both solitary and social insects. How has the function of biogenic amines in solitary insects been coopted for social behaviors? Here, we used Ceratina calcarata, a behaviorally well-studied small subsocial carpenter bee to explore how biogenic amines may play a role in the reproductive shift over a season. We found that as females transition from a pre-reproductive to reproductive state, ovarian development is accompanied by an increase in brain levels of octopamine and serotonin. For comparison, we provide the first characterization of biogenic amines in the brains of males. These results suggest the essential role of biogenic amines in the transition of reproductive states in a bee on the brink of sociality and provide a deeper understanding of how biogenic amines may have influenced the evolution of social behavior.
\end{abstract}

biogenic amines / reproductive status / octopamine / serotonin / incipiently social

\section{INTRODUCTION}

Understanding how proximate mechanism can mediate the transition from solitary to social behaviors is critical to understanding how selective pressures can produce complex societies. The modulation of biogenic amines is one such potential mechanisms, as these neurotransmitters or neurohormones play a significant role in regulating the physiology and behavior of all animals, including insects (Bicker and Menzel 1989;

Corresponding author: C. Cook, cncook1@asu.edu

Chelsea N. Cook and Sarah P. Lawson contributed equally to this work.

Data archival location: Figshare (tbd)

Manuscript editor: James Nieh
Blenau and Baumann 2001; Evans 1980). Because of their fast synaptic transmission (Greengard 2001), biogenic amines can mediate rapid changes in behavior in response to shifting environmental and physiological conditions (Wagener-Hulme et al. 1999). Biogenic amines have been shown to play a critical role in the control and regulation of a wide range of vital functions for solitary insects, including regulation of activity, aggression, nutrition and reproduction in Drosophila melanogaster (Alekseyenko et al. 2014), Manduca sexta (Claassen and Kammer 1986), and Gryllus bimaculatus (Stevenson et al. 2000).

In social insects, biogenic amines play a role not just in individual behaviors, but they also mediate most major group tasks, such as the organization of dominance hierarchies, division of labor, communication, and reproduction. In the 
context of shaping societies, these behaviors are not independent. For example, in queenless ants, reproductives are individuals that have used aggression to achieve social dominance (Okada et al. 2015), and this aggressive behavior status is modulated by dopamine (Cuvillier-Hot and Lenoir 2006; Penick et al. 2014). In Bombus terrestris, dominant reproductive workers have significantly higher octopamine levels compared with workers of lower dominance status (Bloch and Grozinger 2011). Additionally, in the primitively eusocial wasp, Polistes chinensis, dopamine induces ovarian development in workers isolated from the inhibitory stimulus of the natal nest (Sasaki et al. 2009). Among honey bee workers, foragers have significantly higher concentrations of octopamine and tyramine compared to nurses (Scheiner et al. 2017; Wagener-Hulme et al. 1999), and fanners have lower octopamine and tyramine than nonfanners (Cook et al. 2017). Successful group coordination and cooperation relies on communication between individuals, which also may be modulated by biogenic amine levels. In the carpenter ant, Camponotus herculeanus, increased levels of octopamine is associated with increased social interactions and nestmate recognition (Korczynska et al. 2005). In honey bees, increased octopamine levels modulate the waggle dance used to communicate resource value (Barron et al. 2007), enhance responsiveness to brood pheromone, and induce pollen foraging (Barron et al. 2002). Understanding how biogenic amines have been coopted to mediate these social behaviors can help us understand social evolution.

Despite the burgeoning research on the role of biogenic amines in modulating behavior in highly social and solitary organisms, such work is limited in subsocial organisms (Kamhi et al. 2017). Facultatively social organisms can exhibit either solitary or social behaviors, offering a unique opportunity to examine the ecological pressures and evolutionary constraints influencing the onset of social behavior and the mechanisms that drive these transitions (Rehan and Toth 2015). The small carpenter bees, genus Ceratina (Hymenoptera: Apidae), exhibit a range of behaviors, including maternal care, division of labor, mutual tolerance, and kin discrimination. These traits are often posited as preconditions of social complexity
(Michener 1985; Wilson 1971). Some ceratinines are even capable of forming eusocial colonies (Chandler 1975; Sakagami and Maeta 1995). One species that offers great potential for understanding the transition from pre-reproductive to reproductive behavior is Ceratina calcarata, a small carpenter bee endemic to eastern North America (Shell and Rehan 2016). In the spring, a pre-reproductive female will excavate a nest solitarily within a dead broken branch, commonly staghorn sumac, Rhus typhina (Sapindales: Anacardiaceae). Next, the female will begin the active brood stage by laying eggs over a few weeks. She forages to provide each offspring with its own nutrient-rich pollen ball (Rehan and Richards 2010a; Lawson et al. 2016). During this reproductive portion of her life cycle, the mother exhibits subsocial behavior, guarding and grooming her developing offspring (Rehan and Richards 2010a). Such a major behavioral transition is likely to have been a necessary precursor for evolving more complex social behaviors in the ancestors of the eusocial hymenoptera (reviewed in Rehan and Toth 2015).

Because of the essential role biogenic amines play in the organization of social insects, we hypothesize that the transition from pre-reproductive to reproductive behaviors would be associated with changes in brain biogenic amine levels. To test this hypothesis, we compared biogenic amine concentrations from brain tissue representing two different reproductive states in females: 1) early season, prereproductive and 2) late season, reproductive females. We further explored the relationships between ovarian development and shifts in biogenic amines in $C$. calcarata. We predict that dopamine and serotonin will likely be increased in females with active brood, given the increased aggression due to nest defense she may engage in (Rehan and Richards 2013). Further, serotonin may be playing a role in ovary development across the nesting season. As such, we predict serotonin will increase as ovaries increase in size. To generate a broader baseline of the roles played by these amines, we compared both female states to males collected during the active brood season. C. calcarata male never enter a subsocial stage; instead they 
live solitarily in nests from the previous season (Rehan and Richards 2010b) and therefore may have amine profiles similar to the solitary female stage. Overall, this study provides a link between the reproductive transitions in bees and provides a framework for studying other intermediately social insect species.

\section{MATERIALS AND METHODS}

\subsection{Collections and physiological measurements}

Nests of $C$. calcarata were collected from staghorn sumac (Rhus typhina) stands in Durham, New Hampshire, USA $\left(43.1339^{\circ} \mathrm{N}\right.$, $70.9264^{\circ} \mathrm{W}$ ) between May 4 and July 30, 2015. Nests were dissected in the lab and their contents were recorded. This survey included number of brood cells, brood developmental stages, and nest width and length. All adults found at the nest were stored at $-80^{\circ} \mathrm{C}$ for later dissection. Adult females were assumed to be the mother, and their reproductive status was estimated by dissection of the metasoma followed by a measurement $(\mathrm{mm})$ of the three largest terminal oocytes of one ovary to calculate each female's ovary size (Rehan and Richards 2013). Briefly, the ovaries enlarge during egg laying in the active brood stage, and then are resorbed following the breeding season (Withee and Rehan 2016). Sex was determined by counting the number of metasomal terga; females have six segments, while males have seven (Rehan and Richards 2010a). Comparisons between three distinct nest classes were used (Rehan and Richards 2010b). Founding nests were unprovisioned and without brood and were occupied by a single pre-reproductive female with undeveloped ovaries. Active brood nests had a reproductive female with fully developed ovaries and contained at least one pollen ball with an associated egg. Males were discovered singly in nests and were post-reproductive as they mate early in the spring, prior to collection (Rehan and Richards 2010a). We collected 40 pre-reproductive females, 40 reproductive females, and 40 males.

\subsection{Brain dissections and HPLC analysis}

For each nest class, the brains of five bees were pooled as is typical for similarly sized insects to maximize amine detectability, giving us eight samples per group. Briefly, bees were dissected on dry ice to preserve amines. Brains were placed together in $1.5-\mathrm{mL}$ tubes and stored at $-80{ }^{\circ} \mathrm{C}$ until analysis. For analysis, frozen brains were combined with $20 \mu \mathrm{L}$ of chilled $0.2 \mathrm{M}$ perchloric acid and the internal standards dihydroxybenzylamine (DHBA, (87 pg $\mu \mathrm{l}^{-1}$; Sigma-Aldrich, St Louis, MO, USA) and synephrine (50 pg $\mu \mathrm{l}^{-1}$; Sigma-Aldrich). Brains were homogenized using plastic pestles, then sonicated in an ice bath for $5 \mathrm{~min}$. After an additional $20 \mathrm{~min}$ incubation period in the ice bath to complete amine extraction, the brain tissue was pelletized in a chilled $\left(4^{\circ} \mathrm{C}\right)$ centrifuge at $12,000 \mathrm{RCF}$ for $10 \mathrm{~min}$.

We analyzed concentrations of the four most prevalent biogenic amines in insects: dopamine (DA), octopamine (OA), serotonin (5-HT), and tyramine (TA). For each sample, $10 \mu \mathrm{L}$ of the supernatant was injected manually into the highperformance liquid chromatography (HPLC; Coularray 5600A, ESA, Chelmsford, MA, USA) system. Samples from each test group were run consecutively to account for daily variation in the HPLC system sensitivity. The HPLC used a reverse-phase catecholamine HR-80 column (ESA) for amine size separation. Samples were loaded into a $20 \mu \mathrm{L}$ holding loop and injected manually (Rheodyne 9125, Rohnert Park, CA, USA). Individual amines were identified by characteristic responses of a 4-channel electrochemical detector with channel voltages set at 125, 175, 425 , and $650 \mathrm{mV}$. Each amine was quantified using peak areas for the $650 \mathrm{mV}$ channel. The detection limit was $5 \mathrm{pg}$. The mobile phase was composed of $15 \%$ methanol, $15 \%$ acetonitrile, $1.5 \mathrm{mmol}^{-1}$ sodium dodecyl sulfate, $85 \mathrm{mmol} \mathrm{l}^{-1}$ sodium phosphate monobasic, and $5 \mathrm{mmol} \mathrm{l}^{-1}$ sodium citrate and polished water. We used phosphoric acid to adjust $\mathrm{pH}$ to 5.6. The flow

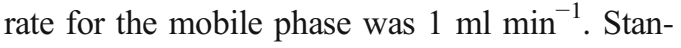
dard curves were calculated from external standards of the hydrochloride forms of DA, OA, 5HT, and TA (Sigma-Aldrich). For a full 
description of this system, see Brent et al. (2016) and Penick et al. (2014).

\subsection{Statistical analysis}

Ovary development, measured as the sum of the lengths of the three largest oocytes, was compared between the two female reproductive stages using a Welch two-sample $t$ test. To compare the amine concentrations of the pre-reproductive females, reproductive females, and males, we first used a Shapiro-Wilk test to test for normality and Levene's test for equality of variance. If the amine concentration response variables were not normally distributed, we used a Kruskal-Wallis test with Dunn's post hoc test or an ANOVA with Tukey post hoc test if the data were normal. To determine the relationship between average ovary size, nest class, and brain biogenic amine concentrations, we used a linear model with a type I sum of squares analysis using the "ANOVA" (R package Car, Fox) function on the linear model. Our response variable is the average ovary size from the five individuals we pooled to perform amine analysis. To ensure that a linear model works with our sample size, we performed a post hoc power analysis and confirmed that our measured effect size and sample size for our significant model for serotonin was at $99 \%$. The overall model for octopamine was not quite significant but still had $47 \%$ power. For each amine, we began with the full model including the ovary size and nest class interaction, then removed insignificant interactions. Bayesian information criterion (BIC) was used to ensure that final models were the optimal model. All reported $p$ values are two-tailed with an alpha value of 0.05 . All statistical analyzes were performed in $\mathrm{R}$ version 3.4.1.

\section{RESULTS}

\subsection{Nest class and ovarian development}

After first using presence of brood to distinguish pre-reproductive from reproductive nests, we used ovarian development to confirm these results. Females collected from founding nests were pre-reproductive, having significantly less developed ovaries than females collected from nests containing actively provisioned brood (Figure 1; $N=40, t=9.31$, df = 67.07, $p<0.0001)$. The median \pm SE ovary size from pre-reproductive females was 0.95 $\pm 0.19 \mathrm{~mm}$, whereas reproductive females had a median \pm SE ovary size of $3.38 \pm 0.12 \mathrm{~mm}$.

\subsection{Biogenic amines profiles across nest class}

To establish a profile of biogenic amine levels across the nest classes, we compared prereproductive females, reproductive females and post-reproductive males (Figure 2; $N=8$ samples for each group). We found a significant difference across groups in the concentrations of octopamine (Kruskal-Wallace: $X^{2}=7.81$, df $=2, p=0.03$ ). Reproductive females had significantly more octopamine than pre-reproductive females (Dunn Test: $Z=2.47, p=0.04$ ) and suggestively more than males $(Z=2.08, p=0.07)$. There was no difference among pre-reproductive females and males $(Z=-0.38, p=0.70)$. Similarly, serotonin levels differed across the three groups $(N=8$, $\left.X^{2}=8.64, \mathrm{df}=2, p=0.01\right)$. Reproductive females had significantly more serotonin than prereproductive females $(Z=3.94, p=0.03)$ and males $(Z=2.55, p=0.02)$. Serotonin did not

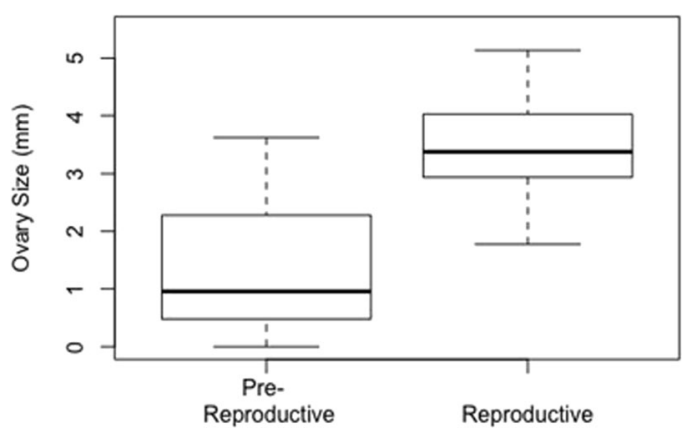

Fig. 1 Reproductive females have significantly larger ovaries than early season, pre-reproductive females. Female $C$. calcarata were collected from nests and qualified as either pre-reproductive if no offspring were present or reproductive if active brood was present (eggs, larvae or pupae). $N=40$ individuals from each group. Bold horizontal bars indicate the medians, while the boxes indicate $25-75$ th percentile, whiskers are 1.5 interquartile ranges (IQR) of the 25 th and 75 th percentile values. 

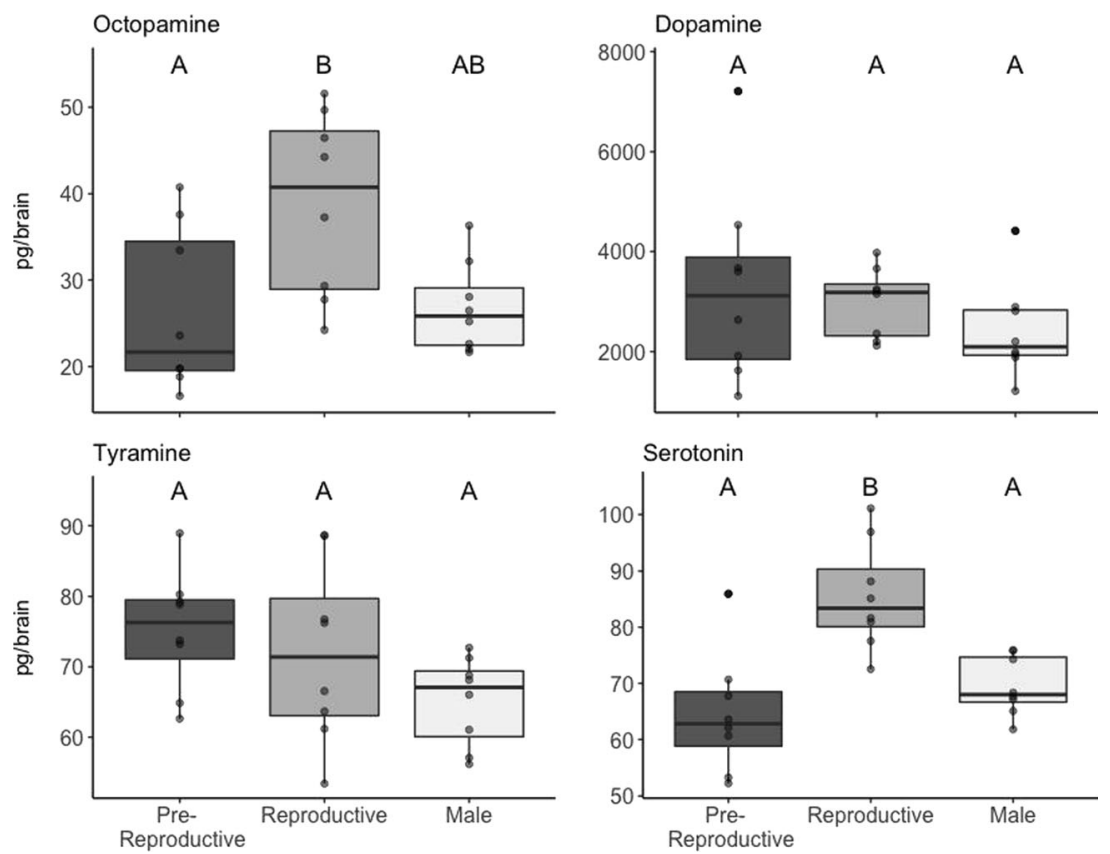

Fig. 2. The concentrations of octopamine, dopamine, tyramine and serotonin in C. calcarata males and in two life stages of females. Letters indicate significant differences as indicated by a Tukey (Octopamine and Dopamine) or Dunn (Tyramine and Serotonin) post hoc tests. Bold horizontal lines indicate the medians, boxes are 25-75th percentile, whiskers are 1.5 interquartile ranges (IQR) of the 25 th and 75 th percentile values.

differ between pre-reproductive females and males $(Z=-0.85, p=0.39)$. In contrast, we found no differences across groups for dopamine $\left(\mathrm{X}^{2}=\right.$ $2.04, \mathrm{df}=2, p=0.36)$ or tyramine $\left(X^{2}=4.68\right.$, $p=0.09$ ).

\subsection{Nest class, ovarian development, and biogenic amine levels}

We found that ovarian development and nest class interact to affect serotonin levels in female bees (Figure 3, whole model, $F_{3,12}=9.56, p=$ 0.001 ; nest class $*$ ovarian development, $F=$ $6.32, p=0.03$; nest class, $F=-3.11, p=0.06$; ovarian development, $F=18.08, p=0.001$ ). The concentration of octopamine tended to be predicted by the nest class of the bee but was not influenced by ovarian development (Figure 3; whole model, $F_{3,12}=2.92, p=0.08$; nest class, $F=5.02, p=0.043$; ovarian development; $F=$ $0.1, p=0.75)$. There was no significant effect of ovarian development, nest class or their interaction on levels of dopamine (overall model,
$F_{3,12}=1.159, p=0.36$ ) or tyramine (overall model, $F_{3,12}=0.23, p=0.88$ ).

\section{DISCUSSION}

Understanding the proximate mechanisms of reproductive status is critical to understanding the evolution of reproductive division of labor. Here, we characterize the role of biogenic amines in a subsocial bee. We found that females actively provisioning brood do have significantly greater ovarian development (Figure 1) and higher concentrations of octopamine and serotonin in their brains (Figure 2) than observed in pre-reproductive females. We also found that levels of serotonin in the brain increases with ovarian development (Figure 3). Though we did not illustrate a causative relationship, these results indicate an associative link between biogenic amine concentrations and reproductive status, suggesting that these neurotransmitters may regulate reproductive behavior.

As $C$. calcarata females progress from their solitary pre-reproductive state to their subsocial 

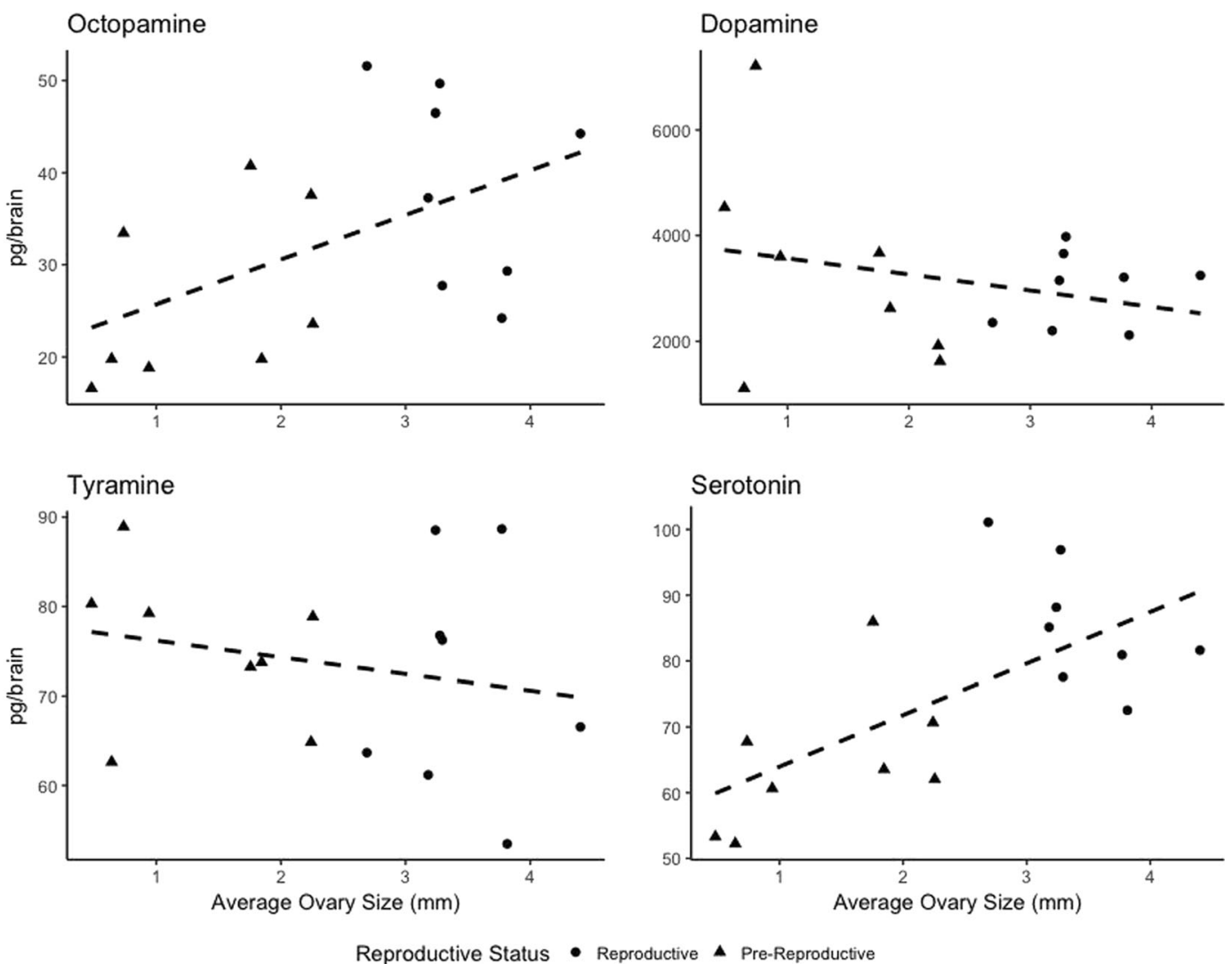

Fig. 3 Ovary size and reproductive status predict the concentration of octopamine and serotonin in the brain. There was no significant effect of ovary size or reproductive status on dopamine or tyramine in the brain. Each point represents pooled samples for biogenic amines. Triangles indicate average ovary size of the five pooled prereproductive individuals for each sample, while circles represent reproductive females. Lines are fit linear models for ovary size and biogenic amine concentration. $N=17$ pooled samples

reproductive state, their ovaries mature and develop the ability to produce eggs (Rehan and Richards 2013). This reproductive shift is accompanied by a behavioral transition from nest construction to foraging and egg-laying. A similar progression is observed in the facultatively social sweat bee Megalopta genalis; pre-reproductive females have smaller ovaries than the reproductive females with which they co-habitate, but once they leave their nest to found their own colony their ovaries enlarge and their behavior changes (Smith et al. 2008). Comparing dispersing reproductives and workers that remain in the colony to care for sisters, dispersing reproductives have larger ovaries than workers (Kapheim et al.
2012). The reduced ovarian development is likely due to the presence of the queen, who exerts social dominance and prevents her daughters from reproducing while at the natal nest (Smith et al. 2009). Dominance hierarchies in subsocial bees are thought to be a necessary precursor to the reproductive and behavioral division of labor facilitating the evolution of social behavior (Withee and Rehan 2016).

We found that in C. calcarata, both octopamine and serotonin are upregulated during the development of ovaries, and thus the shift to reproductive status. Biogenic amines have both physiological and behavioral roles in insects. For example, many factors change along with 
biogenic amines as a honey bee ages, such as brain size, gland size, and concentrations of juvenile hormone and vitellogenin in the hemolymph (Harris and Woodring 1992; Huang et al. 1991; Schulz and Robinson 1999; Amdam and Omholt 2003). In other social bees, octopamine plays an important role in reproductive division of labor. Bombus terrestris workers who become dominant and develop the ability to lay eggs have higher amounts of octopamine than submissive workers (Bloch and Simon, 2000). However, in bumble bees, octopamine levels are also tightly correlated to dominance behavior, while ovarian development is similar in dominant and submissive individuals. During the reproductive phase of the C. calcarata life cycle, the nest foundress exhibits nest defense, which may also be associated by an increase in octopamine. Although not tested directly, the increase in defensive behaviors for females with active brood could be caused by an increase in octopamine levels, an association observed in other arthropods (Bicker and Menzel 1989; Fussnecker et al. 2006). Future pharmacological experiments are needed to disentangle the role of octopamine in the behavioral transition of nest foundresses.

Like octopamine, serotonin modulates many behaviors in invertebrates, including circadian rhythms (Yuan et al. 2005), mating behaviors (Vargas et al. 2010), feeding behaviors (Braun and Bicker 1992), and aggression (Alekseyenko et al. 2014). Serotonin plays a role in cooperative nest defense (Nouvian et al. 2018) and increases as individuals age in honey bees (Wagener-Hulme et al. 1999) and Pheidole dentata ants (Seid and Traniello 2005). When honey bee colonies are queenright, the development of their ovaries is suppressed (Perepelova 1929). A serotonin receptor, Am5HT7, is upregulated in 10- and 15day-old workers from queenless colonies, as well as from individuals that had activated ovaries (Vergoz et al. 2012). A similar trend was found in the primitively eusocial paper wasp, Polistes chinensis, in which both serotonin and dopamine levels increased as ovaries developed (Sasaki et al. 2007). Serotonin, therefore, may play a role in signaling development of ovaries of $C$. calcarata. However, during the reproductive phase, $C$. calcarata engages in nest defense (Mikát et al. 2017; Rehan et al. 2014). Therefore, the increase in serotonin when the female has brood may also be related to nest defense, as serotonin modulates aggressive behavior in other invertebrates (Alekseyenko et al. 2014; Huber 2005).

Because of the limited role of males in most social Hymenoptera, much less is known about their anatomy, physiology, and behavior. In C. calcarata, sons will remain in the nest with their maternal group to overwinter. Males then emerge in early in spring to mate (Rehan and Richards 2010b). Previous work on male insects has focused on the role of biogenic amines on sexual behaviors. In multiple species of moths, increased octopamine levels have been shown to improve pheromone discrimination and orientation (Dolzer et al. 2001; Linn 1997). Similarly, increases in both dopamine and octopamine were associated with sexual maturation and the onset of mating flight behavior in honey bees (Mezawa et al. 2013). We found that $C$. calcarata males produce an intermediate amount of both octopamine and serotonin compared to prereproductive and reproductive females (Figure 2). Although this serves as a baseline for biogenic amine levels in males of a subsocial species, more work is needed to compare specific age-related or social behaviors to amine levels.

In summary, we show that changes to biogenic amines coincide with a significant transition in the life history of a subsocial bee. C. calcarata provides a unique system by which to study the mechanisms that influence the transition from solitary to subsocial physiology and behavior. As this is the first examination of the role of biogenic amines in incipiently social bees, additional studies are needed to understand whether and how the role of biogenic amines vary over time and during development. For example, identifying the specific tissues that these biogenic amines act upon can lead to the development of a more precise picture of how and where these molecules act. In particular, studying the expression of amines in relation to ovarian tissue activity across the colony cycle would facilitate comparison to similar studies in honey bees (Vergoz et al. 2012). Further, while pharmacological studies of this species may be difficult in the field, basic behavioral studies can be undertaken in the lab to define the effects of these biogenic amines on activity, reproduction and aggression. 
Overall, this work offers a crucial foundation for researching the role of biogenic amines in early insect societies.

\section{ACKNOWLEDGEMENTS}

We thank Salena Helmreich, Wyatt Shell, and Jacob Withee for assistance with nest collections.

\section{AUTHOR CONTRIBUTIONS}

CNC, SPL, and SMR conceived the research experiment, collected, and analyzed data and contributed to manuscript preparation. CSB assisted with data interpretation and manuscript preparation. All authors read and approved the final manuscript.

\section{FUNDING INFORMATION}

This work was supported by funding from the University of New Hampshire to SMR, National Science Foundation - Integrative Organismal Systems: Behavioral Systems (1456296) to SMR and National Science Foundation Postdoctoral Research Fellowship (1523664) to SPL. Mention of trade names or commercial products in this article is solely for the purpose of providing specific information and does not imply recommendation or endorsement by the US Department of Agriculture. USDA is an equal opportunity provider and employer.

\section{COMPLIANCE WITH ETHICAL STANDARDS}

Conflict of interest The authors declare that they have no potential conflict of interest in relation to the study in this paper.

Changement des amines biogènes pendant la transition pré-reproductive à reproductive chez la petite abeille charpentière, Ceratina calcarata

Amines biogènes, statut reproducteur, octopamine, sérotonine

Veränderungen bei biogenen Aminen während des Übergans von der prä-reproduktiven zur reproduktiven Phase bei der kleinen Holzbiene Ceratina calcarata.
Biogene Amine, Reproduktionsstatus, Octopamin, Serotonin

Publisher's Note Springer Nature remains neutral with regard to jurisdictional claims in published maps and institutional affiliations.

\section{REFERENCES}

Alekseyenko, O. V., Chan, Y. B., De La Paz Fernandez, M., Bülow, T., Pankratz, M. J. and Kravitz, E. A. (2014). Single serotonergic neurons that modulate aggression in Drosophila . Curr. Biol. 24, 2700-2707.

Amdam, G. V. and Omholt, S. W. (2003). The hive bee to forager transition in honeybee colonies: the double repressor hypothesis. J. Theor. Biol. 223, 451-464.

Barron, A. B., Schulz, D. J. and Robinson, G. E. (2002). Octopamine modulates responsiveness to foraging-related stimuli in honey bees (Apis mellifera). J Comp Physiol A 188, 603-610.

Barron, A. B., Maleszka, R., Meer, R. K. Vander and Robinson, G. E. (2007). Octopamine modulates honey bee dance behavior. Sci. York 104, 1703-1707.

Bicker, G. and Menzel, R. (1989). Chemical codes for the control of behaviour in arthropods. Nature 337, 33-39.

Blenau, W. and Baumann, A. (2001). Molecular and pharmacological properties of insect biogenic amine receptors: Lessons from Drosophila melanogaster and Apis mellifera. Arch. Insect Biochem. Physiol. Arch. Insect Biochem. Physiol. 48, 13-38.

Bloch, G. and Grozinger, C. M. (2011). Social molecular pathways and the evolution of bee societies. Philos. Trans. R. Soc. Lond. B. Biol. Sci. 366, 2155-2170.

Bloch, G. and Simon, T. (2000). Brain biogenic amines and reproductive dominance in bumble bees (Bombus terrestris ). J. Comp. Physiol. A. 186, 261-8.

Braun, G. and Bicker, G. (1992). Habituation of an appetitive reflex in the honeybee. J. Neurophysiol. 67, 588-598.

Brent, C. S., Miyasaki, K., Vuong, C., Miranda, B., Steele, B., Brent, K. G. and Nath, R. (2016). Regulatory roles of biogenic amines and juvenile hormone in the reproductive behavior of the western tarnished plant bug (Lygus hesperus). J. Comp. Physiol. B Biochem. Syst. Environ. Physiol. 186, 169-179.

Chandler, L. (1975). Eusociality in Ceratina calcarata Robertson (Hymenoptera: Anthophoridae). Proc. Indiana Acad. Sci. 84, 283-284.

Claassen, D. E. and Kammer, A. E. (1986). Effects of octopamine, dopamine, and serotonin on production of flight motor output by thoracic ganglia of Manduca sexta. J. Neurobiol. 17, 1-14.

Cook, C. N., Brent, C. S. and Breed, M. D. (2017). Octopamine and tyramine modulate the 
thermoregulatory fanning response in honey bees (Apis mellifera ). J. Exp. Biol. 220, 1925-1930.

Cuvillier-Hot, V. and Lenoir, A. (2006). Biogenic amine levels, reproduction and social dominance in the queenless ant Streblognathus peetersi. Naturwissenschaften 93, 149-153.

Dolzer, J., Krannich, S., Fischer, K. and Stengl, M. (2001). Oscillations of the transepithelial potential of moth olfactory sensilla are influenced by octopamine and serotonin. J. Exp. Biol. 204, 2781-94.

Evans, P. D. (1980). Biogenic Amines in the Insect Nervous System. In Adv. Insect. Physiol. 15, pp. 317-473.

Fussnecker, B. L., Smith, B. H. and Mustard, J. A. (2006). Octopamine and tyramine influence the behavioral profile of locomotor activity in the honey bee (Apis mellifera ). J. Insect Physiol. 52, 1083-1092.

Greengard, P. (2001). The Neurobiology of Slow Synaptic Transmission. Science (80) 294, 1024-1030.

Harris, J. W. and Woodring, J. (1992). Effects of stress, age, season, and source colony on levels of octopamine, dopamine and serotonin in the honey bee (Apis mellifera L.) brain. J. Insect Physiol. 38, 29-35.

Huang, Z. Y., Robinson, G. E., Tobe, S. S., Yagi, K. J., Strambi, C., Strambi, A. and Stay, B. (1991). Hormonal regulation of behavioural development in the honey bee is based on changes in the rate of juvenile hormone biosynthesis. J. Insect Physiol. 37, 733-741.

Huber, R. (2005). Amines and motivated behaviors: A simpler systems approach to complex behavioral phenomena. J. Comp. Physiol. A Neuroethol. Sensory, Neural, Behav. Physiol. 191, 231-239.

Kamhi, J. F., Arganda, S., Moreau, C. S. and Traniello, J. F. A. (2017). Origins of Aminergic Regulation of Behavior in Complex Insect Social Systems. Front. Syst. Neurosci. 11, 1-9.

Kapheim, K. M., Smith, A. R., Ihle, K. E., Amdam, G. V, Nonacs, P. and Wcislo, W. T. (2012). Physiological variation as a mechanism for developmental castebiasing in a facultatively eusocial sweat bee. Proc. Biol. Sci. 279, 1437-46.

Korczynska, J., Szczuka, A., Kieruzel, M., Majczynski, H., Khvorostova, N. and Godzinska, E. J. (2005). Effects of the Biogenic Amines, Dopamine, Tyramine, and Octopamine on the Behavior of Carpenter Ant Workers [Camponotus herculeanus (Hymenoptera: Formicidae)] During Nestmate Reunion Tests Carried Out After A Period of Social Isolation. Sociobiology 45, 409-447.

Lawson, S. P., Ciaccio, K. N. and Rehan, S. M. (2016). Maternal manipulation of pollen provisions affects worker production in a small carpenter bee. Behav. Ecol. Sociobiol. 70, 1891-1900.

Linn, C. E. (1997). Neuroendocrine factors in the photoperiodic control of male moth responsiveness to sex pheromone. In Insect Pheromone Research, pp. 194209. Springer, Boston, MA.

Mezawa, R., Akasaka, S., Nagao, T. and Sasaki, K. (2013). Neuroendocrine mechanisms underlying regulation of mating flight behaviors in male honey bees (Apis mellifera L.). Gen. Comp. Endocrinol. 186, 108-115.

Michener, C. D. (1985). From solitary to eusocial: need there be a series of intervening species? Exp. Behav. Ecol. Sociobiol. 31, 293-305.

Mikát, M., Franchino, C. and Rehan, S. M. (2017). Sociodemographic variation in foraging behavior and the adaptive significance of worker production in the facultatively social small carpenter bee, Ceratina calcarata. Behav. Ecol. Sociobiol. 71, 135.

Nouvian, M., Mandal, S., Jamme, C., Claudianos, C., d'Ettorre, P., Reinhard, J., Barron, A. B. and Giurfa, M. (2018). Cooperative defence operates by social modulation of biogenic amine levels in the honey bee brain. Proc. R. Soc. B Biol. Sci. 285, 20172653.

Okada, Y., Sasaki, K., Miyazaki, S., Shimoji, H., Tsuji, K. and Miura, T. (2015). Social dominance and reproductive differentiation mediated by dopaminergic signaling in a queenless ant. J. Exp. Biol. 218, 1091-1098.

Penick, C. A., Brent, C. S., Dolezal, K. and Liebig, J. (2014). Neurohormonal changes associated with ritualized combat and the formation of a reproductive hierarchy in the ant Harpegnathos saltator. J. Exp. Biol. 217, 1496-1503.

Perepelova, L. (1929). Laying workers, the ovipositing of the queen, and swarming. Bee World 10, 69-71.

Rehan, S. M. and Richards, M. H. (2010a). The influence of maternal quality on brood sex allocation in the small carpenter bee, Ceratina calcarata. Ethology $\mathbf{1 1 6}$, 876-887.

Rehan, S. M. and Richards, M. H. (2010b). Nesting biology and subsociality in ceratina calcarata (Hymenoptera: Apidae). Can. Entomol. 142, 65-74.

Rehan, S. M. and Richards, M. H. (2013). Reproductive aggression and nestmate recognition in a subsocial bee. Anim. Behav. 85, 733-741.

Rehan, S. M. and Toth, A. L. (2015). Climbing the social ladder: The molecular evolution of sociality. Trends Ecol. Evol. 30, 426-433.

Rehan, S. M., Richards, M. H., Adams, M. and Schwarz, M. P. (2014). The costs and benefits of sociality in a facultatively social bee. Anim. Behav. 97, 77-85.

Sakagami, S. and Maeta, Y. (1995). Task allocation in artificially induced colonies of a basically solitary bee Ceratina (Ceratsinidia) okinawana, with a comparison of sociality between Ceratina and Xylocopa (Hymenoptera, Anthophoridae, Xylocopinae). Japanese J. Ecol. 63, 115-150.

Sasaki, K., Yamasaki, K. and Nagao, T. (2007). Neuroendocrine correlates of ovarian development and egglaying behaviors in the primitively eusocial wasp (Polistes chinensis ). J. Insect Physiol. 53, 940-949.

Sasaki, K., Yamasaki, K. and Tsuchida, K. (2009). Gonadotropic effects of dopamine in isolated workers of the primitively eusocial wasp, Polistes chinensis. Naturwissenschaften 96, 625-629.

Scheiner, R., Reim, T., Søvik, E., Entler, B. V, Barron, A. B. and Thamm, M. (2017). Learning, gustatory 
responsiveness and tyramine differences across nurse and forager honeybees. J. Exp. Biol. 220, 1443-50

Schulz, D. J. and Robinson, G. E. (1999). Biogenic amines and division of labor in honey bee colonies: behaviorally related changes in the antennal lobes and agerelated changes in the mushroom bodies. J. Comp. Physiol. A. 184, 481-8.

Seid, M. A. and Traniello, J. F. A. (2005). Age-related changes in biogenic amines in individual brains of the ant Pheidole dentata. Naturwissenschaften 92, 198-201.

Shell, W. A. and Rehan, S. M. (2016). Recent and rapid diversification of the small carpenter bees in eastern North America. Biol. J. Linn. Soc. 117, 633-645.

Smith, A. R., Wcislo, W. T. and O'Donnell, S. (2008). Body size shapes caste expression, and cleptoparasitism reduces body size in the facultatively eusocial bees Megalopta (Hymenoptera: Halictidae). J. Insect Behav. 21, 394-406.

Smith, A. R., Kapheim, K. M., O'Donnell, S. and Wcislo, W. T. (2009). Social competition but not subfertility leads to a division of labour in the facultatively social sweat bee Megalopta genalis (Hymenoptera: Halictidae). Anim. Behav. 78, 1043-1050.
Stevenson, P. A, Hofmann, H. A, Schoch, K. and Schildberger, K. (2000). The fight and flight responses of crick - PubMed Mobile. J Neurobiol. 43, 107-20.

Vargas, M. A., Luo, N., Yamaguchi, A. and Kapahi, P. (2010). A role for S6 kinase and serotonin in postmating dietary switch and balance of nutrients in D. melanogaster. Curr. Biol. 20, 1006-1011.

Vergoz, V., Lim, J. and Oldroyd, B. P. (2012). Biogenic amine receptor gene expression in the ovarian tissue of the honey bee Apis mellifera . Insect Mol. Biol. 21, 21-29.

Wagener-Hulme, C., Kuehn, J. C., Schulz, D. J. and Robinson, G. E. (1999). Biogenic amines and division of labor in honey bee colonies. J. Comp. Physiol. A. 184, 471-9.

Wilson, E. (1971). The Insect Societies. Cambridge, Massachusettes: Belknap/Harvard University Press.

Withee, J. R. and Rehan, S. M. (2016). Cumulative effects of body size and social experience on aggressive behaviour in a subsocial bee. Behaviour 153, 13651385.

Yuan, Q., Lin, F., Zheng, X. and Sehgal, A. (2005). Serotonin modulates circadian entrainment in Drosophila . Neuron 47, 115-127. 